\title{
Prevalence, structure and predictors of posttraumatic stress disorder symptoms in Croatian patients following breast cancer
}

Ljubotina, Damir; Šimunović, Mara

Source / Izvornik: Psychiatria Danubina, 2020, 32, 187 - 196

Journal article, Published version

Rad u časopisu, Objavljena verzija rada (izdavačev PDF)

https://doi.org/10.24869/psyd.2020.187

Permanent link / Trajna poveznica: https://urn.nsk.hr/urn:nbn:hr:131:384362

Rights / Prava: In copyright/Zaštićeno autorskim pravom.

Download date / Datum preuzimanja: 2023-04-26

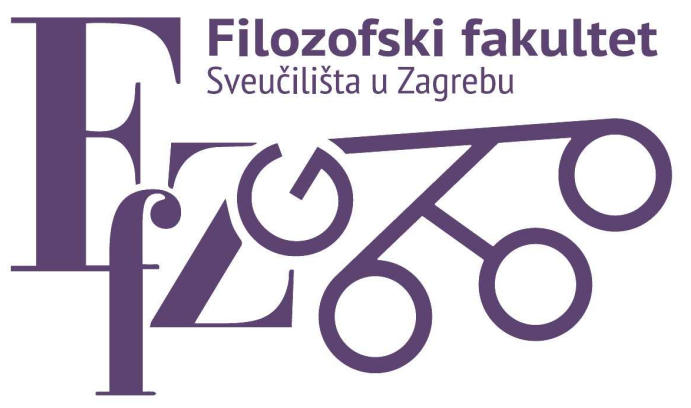

Repository / Repozitorij:

ODRAZ - open repository of the University of Zagreb Faculty of Humanities and Social Sciences
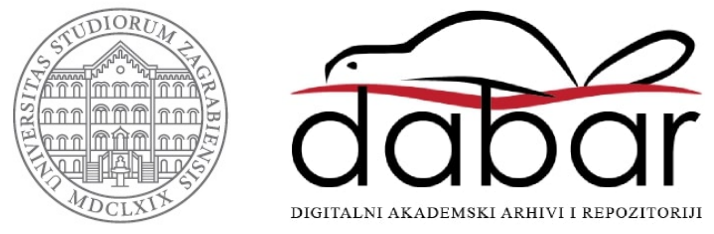


\title{
PREVALENCE, STRUCTURE AND PREDICTORS OF POSTTRAUMATIC STRESS DISORDER SYMPTOMS IN CROATIAN PATIENTS FOLLOWING BREAST CANCER
}

\author{
Mara Šimunović ${ }^{1}$ \& Damir Ljubotina ${ }^{2}$ \\ ${ }^{1}$ Institute of Social Sciences Ivo Pilar, Zagreb, Croatia \\ ${ }^{2}$ Faculty of Social Sciences and Humanities, University of Zagreb, Department of Psychology, Zagreb, Croatia
}

received: 23.11.2018;

revised: 20.12.2018;

accepted: 25.3.2019

\section{SUMMARY}

Background: Breast cancer is the most common cancer in female population worldwide. In the psychological response to the disease some patients may develop Posttraumatic Stress Disorder (PTSD) symptomatology. The aim of this study was to examine the prevalence and structure of PTSD symptoms in Croatian patients following breast cancer and to identify some medical and psychological predictors of severity of these symptoms.

Subjects and methods: 97 women, who were one month up to six years post-completion of all primary cancer therapy, participated in the study. The present research is cross-sectional with a mixed method approach. For the screening of PTSD symptoms PTSD Checklist - Civilian Version (Weathers et al. 1991) was used, with two open-ended questions added.

Results: Using the cutoff method, $21.6 \%$ participants met criteria for PTSD diagnosis. Qualitative analysis indicated future-oriented intrusive thoughts about reoccurrence of cancer, multidimensional nature of cancer as stressors, and hyperarousal symptoms related to internal stimuli. In hierarchical multiple regression analyses, identified predictors accounted for $35.2 \%$ of variability in PCL-C score. PTSD severity was predicted by stressfulness appraisal of the disease $(\beta=0.45 ; p<0.001)$, external health locus of control ( $\beta=0.17$; $p<0.05)$ and self-appraisal of coping with cancer $(\beta=-0.17 ; p<0.05)$. Participants who underwent radical mastectomy $(M=44.41$, $S D=15.5)$ showed higher levels of PTSD than participants who had partial mastectomy $(M=33.47, S D=13.68)$.

Conclusion: Prevalence of PTSD symptoms obtained in this study should be considered as significant, taking into account the lifetime prevalence of PTSD in the general female population. Psychological assessment of women following breast cancer should more often include an assessment of posttraumatic stress reactions. Furthermore, results are in the line with issues of utilizing basic concept of PTSD in the oncology setting, and possible need of reconceptualization of cancer-related PTSD.

Key words: breast cancer - PTSD - Croatia

$* * * * *$

\section{INTRODUCTION}

The recent statistics reported that in Croatia, in 2014, 2644 women were diagnosed with breast cancer (Croatian Institute of Public Health 2016). Breast cancer is the most common cancer worldwide in female population, and the second most common cancer overall (Ferlay et al. 2012). Apart from the medical condition, the process of accepting the cancer diagnosis, treatment and post-treatment period are all associated with problems of psychological adjustment and can interfere with the effectiveness of treatment and recovery. There are three areas of psychosocial impact of breast cancer psychological discomfort (e.g., anxiety, depression, anger); changes in life patterns as a result of psychological difficulties, relationship and sexual problems caused by the disease and reduced activity levels; and fears and concerns related to the loss of the breast, relapse of cancer and death (Meyerowitz 1980). The psychological and somatic stress, negative thoughts and anxiety associated with thinking about death gradually decrease in the first year after the diagnosis (Holland 1998), but psychological symptoms last long after completion of therapy. In the psychological response to the cancer-related stressors some patients may develop symptoms that meet criteria for the psychiatric disorders, with most common being adjustment disorders, depressive and anxiety disorders and Posttraumatic Stress Disorder (PTSD) (Li et al. 2015).

PTSD is defined as a set of distressing symptoms that persist at least a month and occur after direct or indirect exposure to a traumatic event that is fatal, lifethreatening, or that included serious injury or sexual violence. In the most recent Diagnostic and Statistical Manual of Mental Disorder $-5^{\text {th }}$ edition (DSM-5), PTSD is classified as "trauma and stressor related disorder" and some revisions in the diagnostic criteria have been made in comparisons to previous DSM-IV edition (American Psychiatric Association 2013). As the previous edition, DSM-5 includes criteria of intrusion symptoms, persistent avoidance of stimuli associated with the trauma, and hyperarousal, while criterion of negative alterations in cognition and mood has been newly added. PTSD as a psychiatric disorder is most commonly associated with combat experience, and therefore the historical conceptualization of the disorder has followed war conflicts (Begic 2014). In the DSMIII-R, life-threatening illness was excluded as a potential traumatic event that could cause the onset of PTSD symptoms. Diagnostic criteria for PTSD in the DSM-IV 
has put more emphasis on subjective psychological experience of the person rather on traumatic event itself, and since 1994 the PTSD diagnosis begun to be applied to cancer patients. However, despite the since then growing body of studies, research in this area has numerous methodological and conceptual challenges. Applying general PTSD diagnostic category to cancerrelated distress can be problematic because the nature of the life-threating disease as a stressor. Lifelong diseases such as cancer differ from traditional stressors in two basic ways. Firstly, disease is not an external event, which is, on the other hand, true for other traumatic events such as natural disasters, wars or accidents (Wilson \& Keane 1998). Disease is an internal stressor, indivisible from an individual and therefore it can be assumed that the experience of cancer-related stress is qualitatively different from the stress experience caused by other traumatic stressors. The second important difference relates to the possibility that the persistent stress in cancer patients is not a recall of a traumatic event in the past, but the threat of cancer returning or exacerbating. This implies that the threatening event is in the future, while the basic concept of PTSD postulates a trauma that is in the past (Doolittle \& DuHamel 2015). Moreover, studies on PTSD prevalence in cancer patients differ widely with the regard to the type of cancer, time point of the screening and used measures. These differences make general estimation of PTSD rates among cancer patients somewhat complicated and can explain very wide distribution of the reported prevalences (Doolittle \& DuHamel 2015). In the researches that have been included in one of the first review papers on cancer-related PTSD (Kangas et al. 2002), the detected current prevalences of PTSD in women treated for breast cancer ranged between 0 and $30 \%$. In general cancer population the prevalence is estimate to range between 10 and $20 \%$ (Doolittle \& DuHamel 2015). In line with these wide-ranged results, the first objective of this study is to examine the prevalence of PTSD symptoms in Croatian patients following breast cancer, using the Posttraumatic Stress Disorder Checklist - Civilian Version (PCL-C), and to examine the structure of some of the PTSD symptoms in this population by incorporating qualitative measures in the standardized PTSD checklist. Furthermore, there is little knowledge about risk factors for PTSD and clear predictors of the disorder (Doolittle \& DuHamel 2015). There are different models of PTSD, but most of today's interactive models include factors like nature and dimensions of trauma; individual characteristics of the person and features of the social environment (Wilson \& Keane 1998). To contribute to the existing literature on some of these predictive factors in breast cancer population, the second aim of this study is to predict level of PTSD symptoms on the basis of trauma-related factors - i.e., medical variables including invasiveness of treatment and time elapsed since the end of treatment; and individual characteristics - sociodemographic (age, education, marital and financial status), and psychological variables (perceived stressfulness of disease, health locus of control, posttraumatic growth, internal religiosity, and self-appraisal of coping with the disease). Potential predictors were selected on the basis of previous research that identified younger age (Green et al. 1998), lower educational level (Jacobsen et al. 1998), lower income (Cordova et al. 1995), shorter time since completion of cancer treatment (Andrykowski \& Cordova 1998), appraisal of the cancer as highly stressful (Parle et al. 1996) as some of the factors related to PTSD symptoms in cancer population. We also included less frequently investigated variables in breast cancer population such as health locus of control, internal religiosity, and self-appraisal of coping with the disease because of their potential as predicting factors. The posttraumatic growth as potential predictor was examined since its relationship with cancer related stress is still unclear (Cordova et al. 2007).

\section{SUBJECTS AND METHODS}

\section{Subjects}

The participants in this study were women treated for breast cancer who were in remission at the time of the study. It was required that at least 1 month to maximum of 7 years has passed since completion of their primary breast cancer therapy. The lower bound was set because of the DSM criteria for PTSD diagnosis which states that symptoms have to last at least one month post traumatic event. The upper time limit of seven years was determined arbitrarily. Namely, if the five-year survival rate is often considered as a criterion for completely cured (Čufer 2001), it can be assumed that a certain level of anxiety associated with the disease lasts even several years after reaching this rate. We used a convenience sample - all participants were recruited through three associations that bring together women with breast cancer - "EVERYTHING for HER!", "One More Day", and "Europa Donna Croatia". All participants were invited to participate in the study in agreement and with help of the presidents of these three associations. There were three different types of collecting the data. For the participants from the association "EVERYTHING for HER!" who live in Zagreb area, questionnaires were administrated in person. Participants outside Zagreb area who had access to Internet completed questionnaires via online platform. To other participants who do not have access to Internet and are not from Zagreb, consent to participate and questionnaires were sent by post, while majority of them had previously been informed about the survey via telephone. All the participants signed an informed consent which included brief description of the research and research materials, and information that they can cancel the participation in any time. Prior to implementation, the study was approved by the Ethics Committee of Faculty of Humanities and Social Sciences in Zagreb. At the start, the study involved 103 participants from which six participants have been later excluded from all 
the analyses because of their depression diagnosis. Four women refused to participate in the study, citing lack of motivation, fatigue and lack of time as reasons not to participate. The final number of participants with valid data was 97 . We collected 26 questionnaires $(26.8 \%)$ face-to-face, 52 questionnaires $(53.6 \%)$ by online submission and $19(19.9 \%)$ by post. To test if there is a difference in total PCL-C score based on these three methods of data collection, we conducted KruskalWallis test which showed no significant difference $\left(\chi^{2}=0.893 ; \mathrm{p}=0.640\right)$.

Sociodemographic and medical characteristics of the participants are presented in Table 1 . The average age of participants was 50.01 years $(\mathrm{SD}=10.31$; range $=32-75)$, most of them had a secondary (high school) education $(n=50 ; 51 \%)$ and were married or living with a partner $(n=63 ; 64.9 \%)$. The average monthly income per household member was $\mathrm{M}=3173 \mathrm{HRK}(\mathrm{SD}=2307.92$; range $=333-15000)$. The average time elapsed since the end of the primary cancer treatment was $M=26$ months $(S D=20.86$; range $=1-72)$. Majority of participants have undergone partial mastectomy as the type of surgical procedure $(\mathrm{n}=34,35.1 \%)$, and majority received chemotherapy $(n=76,78.4 \%)$.

\section{Instruments}

\section{Sociodemographic and medical data}

We collected the data on participants' age, marital status, education level, number of people living in their household, and total monthly income in their household. Regarding medical information, we asked if they received chemotherapy during their cancer treatment, type of surgery they had, time elapsed since the end of their cancer treatment and if they suffer from any other disease.

\section{PCL - C: Posttraumatic Stress Disorder Checklist - Civilian Version (Weathers et al. 1991)}

Since there is still no validated cutoff scores for the PTSD Checklist for DSM-5 (Ashbaugh et al 2016), we have used PCL-C and the results have been discussed in the framework of symptom-clusters from the DSMIV edition. This checklist contains 17 items based on the DSM-IV symptoms for PTSD and it can be used as a triage questionnaire. First 5 items refer to the symptoms of the cluster B (reexperiencing), the next 7 items refer to the symptoms of the cluster $\mathrm{C}$ (avoidance/ numbing), while last 5 items refer to the symptoms of the cluster D (hyperarousal). Participants use a 5-point Likert scale to rate the extent to which they were bothered in the past month by these 17 symptoms. Civilian version of the scale can refer to any traumatic event, so in this research, questions were keyed to cancer. Based on the findings on specific nature of hyperarousal in cancer-related PTSD (Wilson \& Keane 1998) we added the statement "regarding your physical symptoms" to the $16^{\text {th }}$ item of the PCL-C ("Being super alert or watchful on guard"). The total score can
Table 1. Frequency Statistics for Sociodemographic and Medical Variables

\begin{tabular}{|c|c|c|}
\hline Variables & $\mathrm{n}$ & $\%$ \\
\hline \multicolumn{3}{|l|}{ Age } \\
\hline $32-40$ & 19 & 19.6 \\
\hline $41-50$ & 29 & 29.9 \\
\hline $51-60$ & 33 & 34 \\
\hline $61-70$ & 12 & 12.4 \\
\hline $70+$ & 2 & 2.1 \\
\hline \multicolumn{3}{|l|}{ Education } \\
\hline Elementary education & 6 & 6.2 \\
\hline Secondary education & 50 & 51 \\
\hline Higher level education & 15 & 15.5 \\
\hline College/university degree & 24 & 24.7 \\
\hline Graduate degree & 2 & 2.1 \\
\hline \multicolumn{3}{|l|}{ Marital status } \\
\hline Married/common law & 63 & 64.9 \\
\hline Divorced/separated & 14 & 14.4 \\
\hline Widowed & 5 & 5.2 \\
\hline Never married & 15 & 15.5 \\
\hline \multicolumn{3}{|c|}{ Household monthly income per person } \\
\hline$<4,000$ kuna & 65 & 74.1 \\
\hline $4,000-7,999$ & 18 & 20.7 \\
\hline $8,000-11,999$ & 3 & 3.4 \\
\hline$>12,000$ & 1 & 1.1 \\
\hline \multicolumn{3}{|l|}{ Type of surgery } \\
\hline Lumpectomy & 11 & 11.3 \\
\hline Partial mastectomy & 34 & 35.1 \\
\hline Mastectomy & 22 & 22.7 \\
\hline Radical mastectomy & 29 & 29.9 \\
\hline \multicolumn{3}{|l|}{ Chemotherapy } \\
\hline Yes & 76 & 78.4 \\
\hline No & 21 & 21.6 \\
\hline \multicolumn{3}{|l|}{ Other physical disease } \\
\hline Yes & 33 & 34.0 \\
\hline No & 64 & 66.0 \\
\hline \multicolumn{3}{|c|}{ Time since the end of the treatment } \\
\hline 1 to 6 months & 17 & 17.5 \\
\hline 7 to 12 months & 22 & 22.7 \\
\hline 13 to 24 months & 20 & 20.6 \\
\hline 25 to 36 months & 13 & 13.4 \\
\hline 37 to 48 months & 9 & 9.3 \\
\hline 49 to 60 months & 9 & 9.3 \\
\hline 61 to 72 months & 7 & 7.2 \\
\hline
\end{tabular}

range from 17 to 85 . There are two criteria for determining the indicative result for the possible diagnosis of PTSD. First is the cutoff score criterion where all the results above a certain value are indicative. We have used cutoff score of 50 points, as recommended in validation studies of PCL-C scale on samples of cancer patients (Duhamel et al. 2004). Another criterion is the symptom cluster's criterion where an indicative result contains at least one symptom of the $\mathrm{B}$ cluster, at least three symptoms of the $\mathrm{C}$ cluster and at least two of the D cluster. The symptom meets the threshold if an item endorsement is greater than 3 on the Likert scale. Cronbach's alpha for the PCL-C total score in this study was $\alpha=0.92$ and for subscale scores 
(Reexperiencing, Avoidance/Numbing, and Hyperarousal) $0.88,0.82$, and 0.87 , respectively. These values indicate good internal consistency of the items on the PCL-C scale for the examined sample. We added two open-ended questions to the PLC-C scale that were linked to the first and second item. We asked participants to describe the content of repetitive thoughts and memories related to cancer and to describe the content of recurring dreams related to cancer.

\section{Stress scale}

To attain the subjective response to the traumatic event beyond the level of reactions to everyday stressors, in addition to general measure of stressfulness, we added two more items related to reactions to severely stressful or traumatic events. Therefore the perceived stressfulness of the disease was measured with three items - "When you now remember your experience with cancer (diagnosis, treatment), what would you say, to which extent had you perceived this experience as a threat to your life?"; "To which extent your reaction to this event had included feelings of helplessness or hopelessness? "and "How much in general has the experience of cancer been stressful for you? ". Response scales had 7 degrees. Alpha coefficient of reliability for this scale was $\alpha=0.87$.

\section{Posttraumatic Growth Inventory - Short form (Cann et al. 2010)}

For the purposes of this research, we have translated the shorter form of the scale of posttraumatic growth (PTGI - SF). Posttraumatic growth was first defined as a set of positive changes experienced as a result of coping with a stressful life event (Tedeschi \& Calhoun 1996). The shorter version of the scale consists of 10 items. Two items are associated with each of the five domains of posttraumatic growth changes in life priorities; warmer and more intimate social relationships; more pronounced sense of personal power; new opportunities in life; and spiritual development. Participants were asked to estimate the extent to which they have experienced each of the changes due to their experience with cancer. Answers were on the scale from $0=$ "I did not experience this change" to $5=$ "I experienced this change to a very great degree". Internal reliability of the scale was $\alpha=0.89$.

\section{Scale of intrinsic religiosity}

Intrinsic religiosity was measured with three items: "In my life, I experience the presence of the Divine (i.e., God)", "My religious beliefs are what really lie behind my whole approach to life" and "I try hard to carry my religion over into all other dealings in life". Responses were made on the six-point scale ranged from $1=$ "definitely not true" to $5=$ "definitely true of me". These items are part of the Duke University Religion Index (Koenig \& Bussing 2010). The reliability of this scale was $\alpha=0.95$.

\section{Multidimensional Health Locus of Control Scale - Form C (Wallston et al 1994)}

The scale of multidimensional health locus of control assesses levels of internal locus, external locus associated with significant others (e.g., physicians) and chance external locus of control which refers to the belief that health outcomes are largely influenced by luck or fate (Wallston et al. 1978). In original version, this scale has 18 items - six items are associated with each of the three dimensions of health locus of control. Due to the results of previous research that indicated greater importance of internal and chance external locus of control in the onset of mental disorders in cancer patients (Neipp et al. 2007), we have used only these two subscales represented with five items each. Response scale ranged from $1=$ "I strongly disagree" to $6=$ "I completely agree". C-Form of the scale refers to the specific medical condition, so in the instructions all items were keyed to cancer. The reliabilities for both internal subscale and chance external subscale were $\alpha=0.71$.

\section{Self-appraisal of coping with the disease}

This variable was measured by the item: "How would you rate your ability to cope with the disease?". Response scale ranged from 1 = "very unsuccessful" to 5 = "very successful".

\section{Statistical Analyses}

Data were analyzed using the statistical package IBM SPSS 18.0. To inspect PTSD symptomatology, we used measures of descriptive statistics for each symptom and clusters of symptoms on the PCL-C scale. Answers to open-ended questions were coded with category names that were not preconceived but empirical categories that emerged from the content analysis. Frequencies for each established category were then calculated. To predict PTSD symptom severity, we firstly calculated bivariate correlations between all sociodemographic, medical and psychological variables and PCL-C total scores in order to select the optimal set of potential predictors. Categorical variables - educational level, marital status, type of surgery, chemotherapy treatment and presence of other physical disease were dummy-coded prior to the analysis. Since the variable 'type of surgery' had four categories, one-way analysis of variance (ANOVA) was performed to determine whether PTSD severity differed based on type of surgery participant had. Finally, we carried out hierarchical regression analysis, predicting the total PCL$\mathrm{C}$ score. Since the sample size in this research was relatively small in relation to the number of examined variables, we have omitted the number of predictors entered in the final model. This was done to avoid overfitting of the model which may lead to poor prediction accuracy of the model (i.e., big standard errors) and artificially inflated $\mathrm{R}^{2}$ statistic (Harrell 2001). Therefore, in the regression model we included only predictors identified to be statistically significant in prior analysis. Statistical significance for all analyses was set at $\mathrm{p}<0.05$. 


\section{RESULTS}

\section{Frequency of PTSD symptoms}

Table 2 shows the descriptive statistics for all psychological variables. With the cutoff criterion for the PCL-C, 21 participants out of $97(21.6 \%)$, were likely to meet DSM-IV PTSD criteria. According to the symptom criteria, 31 participants had an indicative result $(32 \%)$ for possible PTSD diagnosis. The mean PCL-C total score was $38.76(\mathrm{SD}=14.08$; range $=17-78)$.

The mean number of endorsed PTSD symptoms was $6.7(\mathrm{SD}=4.87$; range $=0-17)$. Endorsement of a PCL-C item is defined if a symptom is reported to occurred "quite a bit" or "extremely" during the past month. Most frequently endorsed items were $13^{\text {th }}(n=34), 16^{\text {th }}(n=30)$ and $14^{\text {th }}$ item $(n=28)$. Least frequently endorsed items were $3^{\text {rd }}(n=11), 11^{\text {th }}(n=9)$ and $2^{\text {nd }}$ item $(n=6)$ (Table 3$)$.

\section{Responses to the open-ended questions}

58 participants $(59.8 \%)$ answered the first openended question about the content of cancer related thoughts, memories and images. 23 of them reported the fear of recurrence $(39.7 \%) ; 14$ reported the unpleasant memories related to treatment and side effects of treatment (pain, vomiting, hair loss) $(24.1 \%) ; 11$ reported memories of disease triggered by news of somebody else having cancer or dying, or news about cancer in the media and on television $(19 \%) ; 4$ reported sickness that reminds them on chemotherapy, and is caused by certain smells, food or entering the hospital; 4 reported memories of fear and helplessness, and 4 reported the fear of death. The rest of the responses referred to the memory of the moment of hearing about the diagnosis; thoughts of diseases that are triggered by physical pain; memories of the nightmares from the period when they were ill, and other people's reactions on the news of their disease. 9 participants answered the second open-ended question about content of cancerrelated dreams. 8 reported the dreams of recurrence of the disease, and 1 participant reported the dreams of battling the disease.

Table 2. Descriptive Statistics for the Psychological Variables

\begin{tabular}{lcc}
\hline Measure & Observed range (Theoretical range) & $\mathrm{M} \pm \mathrm{SD}$ \\
\hline PTSD - total & $17-78(17-85)$ & $38.76 \pm 14.08$ \\
Cluster B & $5-22(5-25)$ & $10.79 \pm 4.82$ \\
Cluster C & $7-33(7-35)$ & $14.22 \pm 5.92$ \\
Cluster D & $5-25(5-25)$ & $13.75 \pm 5.30$ \\
Posttraumatic growth & $0-50(0-50)$ & $33.85 \pm 10.57$ \\
Internal health locus of control & $8-28(5-30)$ & $17.52 \pm 4.7$ \\
External health locus of control & $5-29(5-30)$ & $18.52 \pm 5.02$ \\
Perceived stressfulness & $3-21(3-21)$ & $14.38 \pm 5.08$ \\
Intrinsic Religiosity & $3-15(3-15)$ & $10.69 \pm 4.01$ \\
Self-appraisal of coping & $1-5(1-5)$ & $4.25 \pm 0.846$ \\
\hline
\end{tabular}

Table 3. Frequencies of Indicative Endorsement of PTSD Symptoms on the PCL - C Scale (N=97)

\begin{tabular}{|c|c|c|}
\hline PCL-C Item & $\mathrm{n}$ & $\%$ \\
\hline 13. Trouble falling or staying asleep & 34 & 35.1 \\
\hline 16. Being "super alert" or watchful on guard & 30 & 30.9 \\
\hline 14. Feeling irritable or having angry outbursts & 28 & 28.9 \\
\hline 17. Feeling jumpy or easily startled & 27 & 27.8 \\
\hline 4. Feeling very upset when something reminded you of a stressful experience from the past & 26 & 26.8 \\
\hline 15. Having difficulty concentrating & 26 & 26.8 \\
\hline 1. Repeated, disturbing memories, thoughts, or images of a stressful experience from the past & 23 & 23.7 \\
\hline 12. Feeling as if your future will somehow be cut short & 23 & 23.7 \\
\hline $\begin{array}{l}\text { 5. Having physical reactions (e.g., heart pounding, trouble breathing, or sweating) } \\
\text { when something reminded you of a stressful experience from the past }\end{array}$ & 18 & 18.6 \\
\hline 9. Loss of interest in things that you used to enjoy & 18 & 18.6 \\
\hline $\begin{array}{l}\text { 6. Avoid thinking about or talking about a stressful experience from the past or avoid having } \\
\text { feelings related to it }\end{array}$ & 16 & 16.5 \\
\hline 7. Avoid activities or situations because they remind you of a stressful experience from the past & 15 & 15.5 \\
\hline 10. Feeling distant or cut off from other people & 14 & 14.4 \\
\hline 8. Trouble remembering important parts of a stressful experience from the past & 12 & 12.4 \\
\hline $\begin{array}{l}\text { 3. Suddenly acting or feeling as if a stressful experience were happening again } \\
\text { (as if you were reliving it) }\end{array}$ & 11 & 11.3 \\
\hline 11. Feeling emotionally numb or being unable to have loving feelings for those close to you & 9 & 9.3 \\
\hline 2. Repeated, disturbing dreams of a stressful experience from the past & 6 & 6.2 \\
\hline
\end{tabular}

Note. Endorsement of a PCL - C item is defined as indicating if a symptom is reported to occurred "quite a bit" or "extremely" during the past month 
Table 4. Correlation Coefficients of Independent Variables and Severity of PTSD Symptoms

\begin{tabular}{|c|c|}
\hline Variable & $\begin{array}{c}\text { PCL-C Total } \\
\text { Score }\end{array}$ \\
\hline \multicolumn{2}{|l|}{ Sociodemographic variables } \\
\hline Age & -0.07 \\
\hline Educational level $^{\mathrm{a}}$ & 0.09 \\
\hline Household monthly income per person & -0.04 \\
\hline Marital status ${ }^{\mathrm{b}}$ & 0.18 \\
\hline \multicolumn{2}{|l|}{ Medical variables } \\
\hline Chemotherapy $^{\mathrm{c}}$ & -0.05 \\
\hline Other physical disease $^{\mathrm{c}}$ & 0.15 \\
\hline Time since the end of the treatment & -0.10 \\
\hline \multicolumn{2}{|l|}{ Psychological variables } \\
\hline Perceived stressfulness of the disease & $0.50 * * *$ \\
\hline Posttraumatic growth & -0.04 \\
\hline Self-appraisal of coping with the disease & $-0.21 *$ \\
\hline Intrinsic religiosity & 0.04 \\
\hline Internal health locus of control & 0.10 \\
\hline External health locus of control & $0.24 *$ \\
\hline \multicolumn{2}{|c|}{$\begin{array}{l}{ }^{a} \text { Coded as } 0=\text { elementary or secondary educational level; } \\
1=\text { higher, college/university or graduate level education. } \\
{ }^{b} \text { Coded as } 0=\text { never married/divorced/widow, } 1=\text { married } \\
\text { or living with a partner. }{ }^{c} \text { Coded as } 0=\text { no; } 1=\text { yes. } \\
{ }^{* * *} p<0.001 ; \quad{ }^{* *} p<0.01 ; \quad{ }^{*} p<0.05\end{array}$} \\
\hline
\end{tabular}

\section{Prediction of PTSD symptom severity}

Table 4 presents the correlation coefficients between the sociodemographic, medical and psychological variables and PTSD severity. The biggest correlation with PCL-C total score was found for the variable 'perceived stressfulness of the disease and cancer treatment' $(\mathrm{r}=0.50, \mathrm{p}<0.001)$. PTSD severity was also significantly associated with chance external health locus of control $(\mathrm{r}=0.24, \mathrm{p}<0.05)$ and self-appraisal of coping with the disease $(\mathrm{r}=-0.21, \mathrm{p}<0.05)$. A one-way ANOVA was conducted to determine if the PTSD severity was different based on type of cancer surgery. Participants were classified into four groups: lumpectomy procedure $(n=11)$, partial mastectomy $(n=34)$, mastectomy $(n=22)$ and radical mastectomy $(n=29)$. PCL-C total score was significantly different between different types of surgery groups: $\mathrm{F}(3,92)=3.956, \mathrm{p}=0.011$. PCL-C score increased from the partial mastectomy $(\mathrm{M}=33.47, \mathrm{SD}=13.68)$ to the mastectomy $(M=37.41, S D=10.62)$, lumpectomy $(M=43.55$, $\mathrm{SD}=12.42)$ and radical mastectomy procedure $(\mathrm{M}=44.41$, $\mathrm{SD}=15.5$ ). Tukey post hoc test revealed that the mean increase from partial to radical mastectomy procedure $(10.94,95 \%$ CI $(2.00,19.89))$ was statistically significant $(\mathrm{p}=0.01)$, but no other group differences were found.

Since there was no correlation between PCL-C total scores and any sociodemographic variables considered as potential covariates, they were not retained in the regression analysis. Variables that significantly predicted PTSD severity were entered in the final hierarchical regression model in the following order - in first block we entered 'dummy' coded categories of type of the received surgery, with partial mastectomy being kept out of the model as the reference category; in the second block we added chance external health locus of control and self-appraisal of coping with the disease; while the perceived stressfulness of the disease was entered in the last block. The full model of was statistically significant, $\mathrm{R}^{2}=0.393, \mathrm{~F}(6,89)=9.62, \mathrm{p}<0.001$; adjusted $\mathrm{R}^{2}=0.352$. Type of cancer surgery accounted for $11 \%$ of the variability in PTSD symptom severity $(\mathrm{p}=0.012)$. The chance health locus of control and self-appraisal of coping with disease, entered in the second step, accounted for an additional $9 \%$ of the variability in PTSD symptom severity $(p=0.008)$, over and above type of undergone surgery. Finally, perceived stressfulness of the disease had the biggest contribution in explaining the PTSD severity, and accounted for an additional $19 \%$ of the PTSD severity variance $(p<0.001)$, over and above type of cancer surgery, external health locus of control and self-appraisal of coping with the disease.

\section{DISCUSSION}

In relation to the first problem of this study, we found prevalence rate of $21.6 \%$ for current, cancerrelated PTSD by using the cutoff method for PCL-C scale, and rate of $32 \%$ when using symptom method. In the validation study of PCL-C on a sample of women

Table 5. Summary of Hierarchical Multiple Regression Predicting PTSD Severity from Type of Surgery, External Health Locus of Control, Self-Appraisal of Coping and Perceived Stressfulness of the Disease

\begin{tabular}{|c|c|c|c|c|c|c|c|c|c|c|c|}
\hline Independent Variables & $\mathrm{B}$ & SE B & $\beta$ & $\mathrm{t}$ & $\mathrm{p}$ & $\mathrm{R}^{2}$ & $\mathrm{~F}$ & $\mathrm{p}$ & $\Delta \mathrm{R}^{2}$ & $\Delta \mathrm{F}$ & $\mathrm{p}$ \\
\hline \multicolumn{12}{|l|}{ First block } \\
\hline Lumpectomy $^{\mathrm{a}}$ & 6.64 & 4.05 & 0.15 & 1.64 & 0.105 & 0.11 & 3.88 & 0.012 & - & - & - \\
\hline Mastectomy $^{\mathrm{a}}$ & 3.12 & 3.09 & 0.09 & 1.00 & 0.316 & & & & & & \\
\hline Radical mastectomy ${ }^{a}$ & 8.78 & 2.92 & 0.28 & 3.00 & 0.003 & & & & & & \\
\hline \multicolumn{12}{|l|}{ Second block } \\
\hline External health locus of control & 0.48 & 0.24 & 0.17 & 2.03 & 0.046 & 0.20 & 4.61 & 0.001 & 0.09 & 5.16 & 0.008 \\
\hline Self-appraisal of coping & -2.82 & 1.41 & -0.17 & -2.00 & 0.048 & & & & & & \\
\hline \multicolumn{12}{|l|}{ Third block } \\
\hline Perceived stressfulness of the disease & 1.24 & 0.24 & 0.45 & 5.27 & $<0.001$ & 0.39 & 9.62 & $<0.001$ & 0.19 & 27.79 & $<0.001$ \\
\hline
\end{tabular}


treated for breast cancer (Andrykowski et al. 1998) better diagnostic efficiency was found when using cutoff method than when using symptom method, which regularly gives higher prevalence. Prevalence of $21.6 \%$ is relatively high in comparison with the results in other studies. In the review paper that included 21 studies (Kangas et al. 2002), prevalence greater than $20 \%$ was found in only two of them. Even though the checklists may result in over-diagnosis (Doolittle \& DuHamel 2015), prevalence obtained in this study should not be dismissed, taking into account that the lifetime prevalence of PTSD in the general female population ranges between 1 and 3\% to 9.7\% (Helzer et al. 1987, according to Begic 2011).

Most frequently endorsed PTSD symptoms in this study were "trouble falling or staying asleep", "being superalert, or watchful or on guard" and "feeling irritable or having angry outbursts". These results are largely consistent with the results of research by Cordova et al. (1995), in which $13^{\text {th }}$ and $16^{\text {th }}$ item of PCL-C were also among three most frequently endorsed. It is clear that the most frequent symptoms in both researches are symptoms of the cluster D. This may be due to the fact that symptoms of D cluster are not specific only for PTSD, but can also be part of other disorders, usual mood fluctuations and somatic complaints.

Previous studies suggest that PTSD caused by the experience of life-threatening diseases is conceptually different from PTSD caused by other traumatic stressors. The main difference is that the disease is an internal stressor and the threat of the disease is prolonged and focused on the future. Responses to the open-ended questions regarding the content of intrusive thoughts confirmed this theory. The largest number of participants, $39.7 \%$ of them, did not report memories of the traumatic event, as it is the case with common clinical features of the disorder, but the fear of recurrence, which indicates the orientation towards the future. $24.1 \%$ of participants reported intrusive memories related to treatment and side effects of treatment. This finding indicates multidimensional nature of cancer as stressor - traumatic can be not only the information of the diagnosis, but also the whole process of treatment and possible side effects.

It has previously also been reported that survivors of cancer are not hyperalert to their environment, but to the changes in their bodies (Wilson \& Keane 1998). Therefore, to the $16^{\text {th }}$ item of the PCL-C ("Being super alert or watchful on guard") we added - "regarding your physical symptoms". This symptom was endorsed in $28 \%$ of participants. Cancer patients often report constant search of lumps on their body, concerns about moles, depigmentation or any other changes that might indicate a recurrence of the disease (Wilson and Keane, 1998).

In addition to conceptual differences of cancer-related PTSD reflected in our qualitative data, additional problem that we recognize is the defining the time framework of cancer as traumatic even. As we mentioned, the diagnosis can be traumatic, but also the entire treatment that can last for a very long time. This, in addition of persisting possibility of cancer recurrence, makes clear defining of when the objective threat ended very difficult. Although some previous studies on cancer-related PTSD have included patients who were still in the process of treatment (e.g., Brewin et al. 1998, CostaRequena \& Gil 2009, Gonçalves et al. 2011) we find it more meaningful to include at least those patient in whom the primary treatment (chemotherapy, surgery, radiation) is completed and therefore the most direct threat is removed. All of the mentioned conceptual challenges raise a question of possible need for reconceptualization of cancer-related PTSD and adaptation of screening instruments for oncology population.

Second aim in this study was to predict the severity of PTSD symptoms based on some medical and psychological characteristics. PCL-C score was predicted the most by the perceived stressfulness of the disease and treatment, even when controlling for type of cancer surgery and other significant psychological characteristics. Association between subjective level of stress and PTSD symptoms in cancer patients has been confirmed in other studies. Lebel et al. (2008) showed that the assessment of disease related stress measured 3, 7, 11 and 15 months after diagnosis predicted the level of intrusion and avoidance symptoms even up to six years after diagnosis. It is important to note that subjective response to trauma is no longer included in PTSD criteria in DSM-5 (American Psychiatric Association 2013), while in DSM-IV, criterion A2 required an experience of "intense fear, helplessness or horror" for a PTSD diagnosis (American Psychiatric Association 2000). This change may be very important in cancerrelated PTSD, since the research show that appraisal of the cancer as highly stressful is associated with fear of cancer progression and recurrence, which can cause distress even years after diagnosis (Doolittle \& DuHamel 2015). Results in our study confirm the importance of stressfulness appraisal in predicting the PTSD severity in cancer population.

We also found that compared to partial mastectomy, radical mastectomy was associated with higher levels of PTSD symptoms. In research by Shelby et al. (2008) there were more cancer patients who received radical mastectomy in group with PTSD symptomatology, than in subsyndromal group and group without PTSD symptoms. Findings in other studies are mixed - Moyer \& Salovey (1996) found lumpectomy procedure, in comparisons to mastectomy, to be associated with higher distress in women with breast cancer. Cohen and colleagues (2000) also found that women who had breast conservation surgery reported greater levels of psychological distress than did women who received a mastectomy, and in some studies no association was found (e.g., Cordova et al. 1995). It seems that radical mastectomy and lumpectomy emerge as two procedures related to higher levels of distress. Moreover, it is 
possible that women who receive lumpectomy can have high level of fear and anxiety about recurrence of the disease and this could be the factor that contributes to development of PTSD-like symptoms and not the invasive of the procedure as in case of radical mastectomy. This could potentially explain no found difference in PTSD symptoms in these two groups of patients in our study. Contribution of the type of undergone surgery in predicting PTSD symptoms is relatively small in comparison to the contribution of previously discussed stressfulness appraisal. In studies of some other trauma events, levels of psychopathology were not related to the intensity of physical injury or disease (Green 1994). Although in cancer population medical factors seem to have some influence on development of PTSD symptoms, subjective response and individual traits still have a greater impact in onset of PTSD symptomatology.

We further found that higher attributions of cancerrelated health outcomes to pure chance were associated with more severe PTSD symptoms. Thinking about the possibility of recurrence as something that is determined by unfortunate circumstances can increase the level of uncertainty and fear which may contribute to development of PTSD symptoms. Although we did not found any research linking dimensions of health locus of control and PTSD symptoms in women treated for breast cancer, research on other trauma survivors confirm this finding (Crisson \& Keefe 1988, Maercker \& Herrle 2005).

Higher self-appraisal of coping with cancer was slightly, but significantly associated with fewer PTSD symptoms. In the framework of self-efficacy theories, self-appraisal of coping capabilities can affect the intensity and persistence of stress reactions in threatening situations, because perception of a threat is not only an inherent property of the situation, but it also depends on the perception of our control over the event (Benight \& Bandura 2003). Furthermore, since it has been shown that optimism as a personality trait is associated with fewer PTSD symptoms (Thomas \& Britt 2011) it is possible that patients who evaluated their coping as better are by nature more optimistic and thus less prone to develop symptoms of PTSD.

Finally, since there was no found relationship between PTSD symptoms and posttraumatic growth, our study supports the view of the multidimensionality of psychological adjustment to trauma - traumatic stress may lead to pathological symptoms, personal growth, or both phenomena (Cordova et al. 2007).

\section{Limitations}

The main limitation of this study is the questionable representativeness of the used sample. The found prevalence of PTSD should be considered with caution since it was obtained on a small and convenient sample that included only participants who are members of associations that bring together women treated for breast cancer. It is possible that these women differ significantly in some variables associated with psychological adjustment to the disease from women who had not sought the support of such organizations. This difference in examined sample could have led to an overestimation of the prevalence of PTSD symptoms. Furthermore, PCL-C is a triage questionnaire that has a good diagnostic efficiency in cancer population, but it cannot replace The Structured Clinical Interview for the DSMIV Axis I Disorders (SCID), which is considered to be the gold standard when setting the formal diagnosis (Doolittle \& DuHamel 2015). In providing more accurate information on the prevalence of PTSD in women treated for breast cancer, future research should include bigger sample of participants who are heterogeneous in their characteristics, and should use clinician-administered instruments in combination with self-reported measures.

\section{CONCLUSIONS}

The present results contribute to the literature on cancer-related PTSD. Despite the small, convenient sample and previously mentioned methodological issues in screening for cancer-related PTSD, prevalence of PTSD symptoms obtained in this study should not be dismissed, taking into account the lifetime prevalence of PTSD in the general female population. Qualitative data obtained in this study highlights the conceptual challenges of PTSD in oncology setting. Namely, these issues involve the presence of multiple stressors in cancer as trauma, ongoing perception of threat that is oriented to the future and manifests primarily as fear of reoccurrence, and hyperarousal symptoms oriented to the person and not the environment. We also identified important predictors of PTSD symptoms in breast cancer patients, with most important of them being the stressfulness appraisal of the disease and treatment. Since subjective response to the traumatic event is no longer included DSM criteria for PTSD this might affect the applicability of these criteria in screening for PTSD in oncology population. Finally, significant rates of PTSD symptoms in cancer patients suggests that psychological assessment and care for women following breast cancer should more often include an assessment of posttraumatic stress reactions and future research should attempt to identify more protective and risk factors in development of PTSD symptoms in this population.

\section{Acknowledgements:}

We would like to acknowledge the valuable efforts and help of Mrs Ljiljana Vukota, MPsy, Head of the Psychological Support Center of the Association "EVERYTHING for HER!," Mrs Danijela Štajner, the Presidents of the Association "One More Day", and Mrs Mira Blažinović and Mrs Ružica Filković from the "Europe Donna Croatia" in recruitment of the participants and collecting the data for this study. 
Conflict of interest: None to declare.

\section{Contribution of individual authors:}

Research design: Mara Šimunović \& Damir Ljubotina.

Data collection: Mara Šimunović.

Statistical analysis and interpretation of data: Mara

Šimunović \& Damir Ljubotina.

Manuscript writing: Mara Šimunović.

Critical revision: Damir Ljubotina.

Approval of the final version: Damir Ljubotina.

\section{References}

1. Andrykowski MA \& Cordova MJ: Factors associated with PTSD symptoms following treatment for breast cancer: A test of the Andersen model. J Trauma Stress 1998; 11:189-203

2. Andrykowski MA, Cordova MJ, Studts JL \& Miller TW: Posttraumatic Stress Disorder after Treatment for Breast Cancer: Prevalence of Diagnosis and Use of the PTSD Checklist - Civilian Version $(P C L-C)$ as a Screening Instrument. J Consult Clin Psychol 1998; 66:586-90

3. Ashbaugh AR, Houle-Johnson S, Herbert C, El-Hage W \& Brunet A: Psychometric Validation of the English and French Versions of the Posttraumatic Stress Disorder Checklist for DSM-5 (PCL-5). PLoS One 2016; 11:1-16

4. Begić D: Psychopathology (2nd rev. ed.). Medicinska naklada, Zagreb, 2014

5. Benight CC \& Bandura A: Social cognitive theory of posttraumatic recovery: The role of perceived self-efficacy. Behav Res Ther 2003; 42:1129-48

6. Brewin CR, Watson $M$, McCarthy $S$, et al: Intrusive memories and depression in cancer patients. Behav Res Ther 1998; 36:1131-42

7. Cann A, Calhoun LG, Tedeschi RG, Taku K, Vishnevsky T, Triplett KN et al.: A short form of the Posttraumatic Growth Inventory. Anxiety Stress Coping 2010; 23:127-37

8. Cohen L, Hack TF, de Moor C, Katz J \& Goss PE: The Effects of Type of Surgery and Time on Psychological Adjustment in Women after Breast Cancer Treatment. Ann Surg Oncol 2000; 7:427-34

9. Cordova MJ, Andrykowski MA, Kenady DE, McGrath PC, Sloan DA \& Redd WH: Frequency and Correlates of Posttraumatic-Stress-Disorder-Like Symptoms After Treatment for Brest Cancer. J Consult Clin Psychol 1995; 63:981-86

10. Cordova MJ, Giese-Davis CJ, Golant CM, Kronenwetter $C C$, Chang CV \& Spiegel CD: Breast Cancer as Trauma: Posttraumatic Stress and Posttraumatic Growth. J Clin Psychol Med Settings 2007; 14:308-19

11. Costa-Requena G \& Gil F: Posttraumatic stress disorder symptoms in cancer: psychometric analysis of the Spanish Posttraumatic Stress Disorder Checklist-Civilian version. Psychooncology 2009; 19:500-07

12. Crisson JE \& Keefe FJ: The relationship of locus of control to pain coping strategies and psychological distress in chronic pain patients. Pain 1988; 35:147-54

13. Croatian National Cancer Registry: Cancer Incidence In Croatia 2014., Bilten 39 [Internet]. Croatian Institute of Public Health, Zagreb, 2016. Available from:
http://hzjz.hr/wp-content/uploads/2013/11/Bilten-

2012 final.pdf, accessed April 2017

14. Čufer T: Breast Cancer. Medicus 2001; 10:173-78

15. Doolittle MN \& DuHamel KN: Post-traumatic Stress Disorder Associated with Cancer Diagnosis and Treatment. In: Holland JC,. Psycho-Oncology. 3rd ed. Oxford University Press, Oxford, 2015, p.323-39

16. Duhamel KN, Ostrof J, Ashman T, Winkel G, Mundy EA, Keane TM, et al: Construct Validity of the Posttraumatic Stress Disorder Checklist in Cancer Survivors: Analyses Based on Two Samples. Psychol Assess 2004; 16:255-66

17. Ferlay J, Soerjomataram I, Ervik M, et al.: GLOBOCAN 2012 v1.0, Cancer Incidence and Mortality Worldwide: IARC CancerBase No. 11 [Internet]. International Agency for Research on Cancer, Lyon, 2013. Available from: http://globocan.iarc.fr, accessed May 2017

18. Gonçalves $V$, Jayson $G$ \& Tarrier $N$ : A longitudinal investigation of posttraumatic stress disorder in patients with ovarian cancer. J Psychosom Res 2011; 70:422-31

19. Green BL: Psychosocial research in traumatic stress: An update. J Trauma Stress 1994; 7: 341-62

20. Green BL, Rowland JH, Krupnick JL, Epstein SA, Stockton P, Stern NM et al: Prevalence of posttraumatic stress disorder (PTSD) in women with breast cancer. Psychosomatics 1998; 32:102-11

21. Harrell FE Jr: Regression modeling strategies. SpringerVerlag, New York, 2001

22. Holland JC: Psycho-oncology. 1st ed. Oxford University Press, Oxford, 1998

23. Jacobsen PB, Widows MR, Hann DM, Andrykowski MA, Kronish LE \& Fields K: Posttraumatic stress disorder symptoms following bone marrow transplantation for breast cancer. Psychosomatic Medicine 1998; 60:366-71

24. Kangas M, Henry JL \& Bryant RA: Posttraumatic stress disorder following cancer. A conceptual and empirical review. Clin Psychol Rev 2002; 4:499-524

25. Koenig HG \& Bussing A: The Duke University Religion Index (DUREL): A Five - Item Measure for Use in Epidemiological Studies. Religions 2010; 1:78-85

26. Lebel S, Rosberger Z, Edgar L \& Devins GM: Predicting stress-related problems in long-term breast cancer survivors. J Psychosom Res 2008; 65:513-23

27. Li M, Hales $M \&$ Rodin G: Adjustment Disorders. In: Holland JC,. Psycho-Oncology. 3rd ed. Oxford University Press, Oxford, 2015, p. 274-80

28. Maercker A \& Herrle J: Long - term effects of the Dresden bombing: Relationship of control beliefs, religious belief, and personal growth. J Trauma Stress 2003; 16:579-87

29. Meyerowitz BE: Psychosocial correlates of breast cancer and its treatments. Psychol Bull 1980; 87:108-31

30. Moyer A \& Salovey P: Psychosocial sequelae of breast cancer and its treatment. Ann Behav Med 1996; 18:110-25

31. Neipp MC, Lopez-Roig $S \&$ Pastor MA: Control beliefs in cancer: A literature review. Anuario de Psicología 2007; 38:333-55

32. Parle M, Jones B \& Maguire P: Maladaptive coping and affective disorders among cancer patients. Psycholog Med 1996; 26:735-44

33. Shelby RA, Golden-Kreutz DM \& Andersen BL: PTSD diagnoses, subsyndromal symptoms, and comorbidities contribute to impairments for breast cancer survivors. $J$ Trauma Stress 2008; 21:165-72 
34. Tedeschi $R G$ \& Calhoun LG: The Posttraumatic Growth Inventory: measuring the positive legacy of trauma. $J$ Trauma Stress 1996; 9:455-71

35. Thomas JL, Britt TW, Odle-Dusseau H \& Bliese PD: Dispositional optimism buffers combat veterans from the negative effects of warzone stress on mental health symptoms and work impairment. J Clin Psychol 2011; 67:866-80

36. Wallston KA, Stein MJ \& Smith CA: Form $C$ of the MHLC Scales: A Condition - Specific Measure of Locus of Control. J Pers Assess 1994; 663:534-53

37. Wallston KA, Wallston BS \& DeVellis R: Development of the Multidimensional Health Locus of Control (MHLC) scales. Health Educ Monogr 1978; 6:160-70

38. Weathers FW, Huska JA, Keane TM: PCL-C for DSM-IV. National Center for PTSD - Behavioral Science Division, Boston, 1991

39. Wilson JP \& Keane TM: Assessing psychological trauma and PTSD (1st ed.). The Guilford Press, New York, 1997

Correspondence:

Research Ass. Mara Šimunović, Mpsy

Institute of Social Sciences Ivo Pilar

Trg Marka Marulića 19/I, 10 000, Zagreb, Croatia

E-mail:mara.simunovic@pilar.hr 